\title{
Ethnic differences in peak expiratory flow rate in Birmingham factory workers
}

\author{
S. H. D. JACKSON* \\ M.B., M.R.C.P. \\ J. K. CRUICKSHANK $\dagger$
M.B., M.R.C.P.
}
D. G. BEEVERS
M.D., F.R.C.P.

L. T. BANNAN $\ddagger$

M.B., M.R.C.P.I.

University Department of Medicine, Dudley Road Hospital, Birmingham

\begin{abstract}
Summary
Among 698 Birmingham factory workers, Asian men $(n=75)$ tended to have lower peak expiratory flow rates (PEFR) than black $(n=156)$ or white $(n=138)$ men when age, height and smoking habits were accounted for. This trend reached statistical significance in Asian females $(n=20)$, despite a small sample size. There were no significant differences in PEFR between blacks and whites of either sex.
\end{abstract}

KEY WORDS: peak expiratory flow, ethnicity.

\section{Introduction}

The study of differences in common diseases in the 3 main ethnic groups in Britain (whites, black West Indians and Asians) has, in recent years, allowed a greater understanding of the diseases themselves. Furthermore, such study has exposed startling differences hitherto unproved and often unsuspected (Beevers, 1981). Admission rates for asthma to a district general hospital serving a triracial population were approximately 3 times higher for Asians and twice as high for black West Indians as for whites (Jackson, Bannan and Beevers, 1981). We therefore decided to include measurement of peak expiratory flow rate (PEFR) in a factory screening survey of blood pressure and cardiovascular risk factors being carried out in the same triracial community.

\section{Methods}

Ten factories and other workplaces were screened representing $72 \%$ of those on the payroll. Each

Present address: *Department of Clinical Pharmacology, St. Bartholomew's Hospital, London; †Department of Medicine, Central Middlesex Hospital, London; †Department of Medicine, Letterkenny General Hospital, Eire. employee was asked to answer a questionnaire concerned with cardiovascular risk factors (including daily cigarette consumption) and ethnic group was noted. Ethnic groups were defined as black (blacks, or their parents, born in the West Indies), white (whites born in the British Isles) or Asian (born, or their parents born, in India, Pakistan, Bangladesh or East Africa). Those not included in these groups were excluded from the analysis. In addition, height, weight, age and PEFR were recorded. A minimum of 3 measurements of PEFR was taken using the Wright miniature peak flow meter (Wright, 1978) and the highest was used in the analysis. If the highest was the last reading, repeated measurements were taken until there was no further increase.

Statistical analysis was performed using the Statistical Package for the Social Sciences version 8.2 on the Queen Mary College (University of London) computer.

\section{Results}

Fewer Asians were screened than either blacks or whites and only 20 Asian females were included (Table 1). This was a reflection of the study population rather than a biased sample. Ethnic differences were seen in mean age, height, PEFR and smoking habits (Table 1). Multiple regression analysis was performed with PEFR as the dependent variable and age, height and daily cigarette consumption the continuous independent variables.

When age, height and smoking habits were allowed for using multiple regression analysis, there were no differences in PEFR between blacks and whites. Asian men however had PEFR values 20 litre/min lower than whites and blacks, although this did not reach statistical significance (Table 2). A similar pattern was seen for Asian females with values $48 \mathrm{litre} / \mathrm{min}$ lower than other women $[F(1,327)=6.8, P<0.01]$ (Table 2). Age, age ${ }^{2}$, height 
TABLE 1. Ethnic differences in mean age, height, smoking habits and PEFR of study sample

\begin{tabular}{|c|c|c|c|c|c|c|}
\hline & \multicolumn{3}{|c|}{ Males } & \multicolumn{3}{|c|}{ Females } \\
\hline & $\begin{array}{c}\text { Black } \\
(n=156)\end{array}$ & $\begin{array}{c}\text { White } \\
(n=138)\end{array}$ & $\begin{array}{c}\text { Asian } \\
(n=75)\end{array}$ & $\begin{array}{c}\text { Black } \\
(n=99)\end{array}$ & $\begin{array}{l}\text { White } \\
(n=210)\end{array}$ & $\begin{array}{c}\text { Asian } \\
(n=20)\end{array}$ \\
\hline Age (years) & $44 \cdot 7$ & $41 \cdot 1$ & $33 \cdot 2$ & $40 \cdot 9$ & $38 \cdot 8$ & $32 \cdot 3$ \\
\hline Height $(\mathrm{cm})$ & $168 \cdot 1$ & 172.9 & 166.8 & $159 \cdot 1$ & $158 \cdot 3$ & 156.5 \\
\hline Smokers (\%) & 53.9 & 50.4 & $21 \cdot 3$ & $15 \cdot 2$ & $49 \cdot 3$ & $5 \cdot 0$ \\
\hline PEFR (litre/min) & 518 & 525 & 516 & 402 & 401 & 372 \\
\hline
\end{tabular}

and daily cigarette consumption all had a statistically significant effect on the multiple regression equation for both men and women (Table 2). Although the F value for age in the women fell below the $5 \%$ significance level (Table 2), the 2 age terms together make a significant contribution to the equation and account for a greater proportion of variance than age alone.

TABLE 2. Multiple regression analysis of PEFR showing regression coefficient (B), F value and significance level for each independent variable.

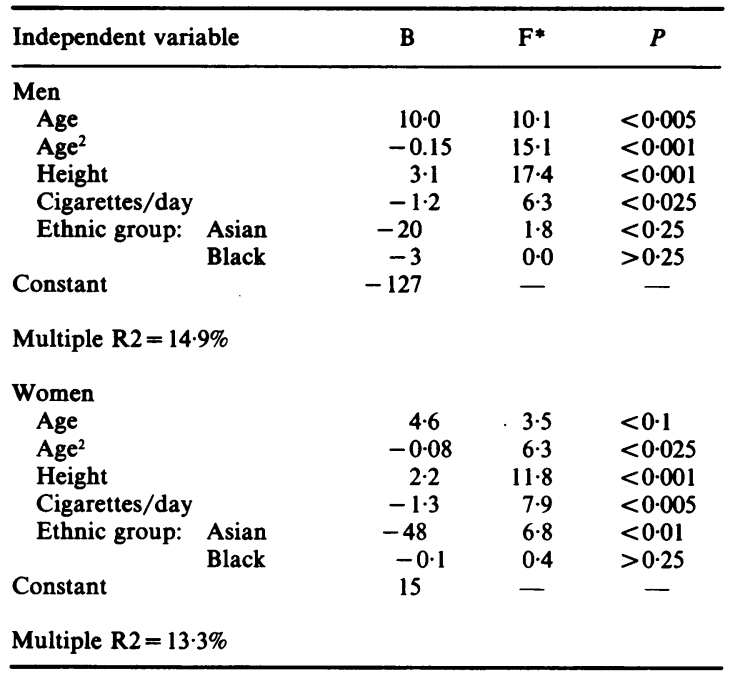

*Men, F (1,362); women, F (1,327).

\section{Discussion}

One of the problems of comparing biological variables in different ethnic groups is the formulation of the hypothesis under test. Is an actual difference sought or an independent effect of ethnic group sought? Mean PEFR values were almost identical in the 3 main groups yet smoking habits varied markedly and there were also differences in age and height. We chose to look for independent effects of ethnic group and therefore relied on multiple regression analysis. This technique has been used fre- quently in the past for both predictive and descripțive purposes.

Gregg and Nunn (1973) used the technique $\overrightarrow{c_{2}^{2}}$ produce multiple regression equations based on data from strictly 'normal' individuals. From these equुations they constructed standard curves showing the relationship between PEFR and age for differeht heights. Their equations used polynomial terms - $\mathrm{age}^{2}$ and $\mathrm{age}^{3}$ for men and $\mathrm{age}^{2}$ for women. the cubic term was rejected in our analysis as it did mbt contribute significantly to the regression equation. The use of the age $^{2}$ term is not merely a statistical manoeuvre as it provides the regression line of PEBR on age with a peak (usually in the fourth decade) $\frac{-}{-} \mathrm{a}$ fact well known to clinicians. The importance of such a term in a multiple regression equation is clear: if an equation without such a term is plotted, it beogemes apparent that PEFR either increases or decteases with age throughout the age range-a phenoriengn not observed in practice.

We found no differences in PEFR between blaêts and whites in either sex and multiple regression analysis confirmed the absence of an independônt effect of ethnic group on PEFR.

It has long been established that vital capacities $\overrightarrow{\text { Prre }}$ lower in black than white Americans (Gould, 1869), but a difference in PEFR or forced expiratgry volume in $1 \mathrm{~s}\left(\mathrm{FEV}_{1}\right)$ : forced vital capacity (FVC) ratio has not been consistently reported. Abramowi et al. (1965) showed lower FVC and FEV, valuesin American black males but measures of airways obstruction-FEV $/$ FVC ratio and PEFR-wore similar to white males. Damon (1966) also found difference in $\mathrm{FEV}_{1} / \mathrm{FVC}$ ratio between blacks agd whites although mid-expiratory flow rates were lower in blacks than whites.

Amongst Asian men, the mean PEFR was mar nally lower than for whites (Table 1) despite being (્ân average 11 years younger. When age and otker variables were taken into account, Asian males ho PEFR values on average 20 litres/min lower thaln whites (Table 2). This difference did not reach statistical significance but suggests that there well be a genuine ethnic difference. Clearly, such a difference would not be of clinical relevance in individual patients. This trend is in keeping with the 
findings of Malik, Moss and Lee (1972) who found lower PEFR values among 'normal' West Pakistani males working in the United Kingdom when compared with data collected by other authors in whites all over the world. This study did not compare ethnic groups within the same community. Cotes and Malhotra (1965) compared a variety of lung function tests in whites with those of Indians. Measures of airways obstruction, $\mathrm{FEV}_{1} / \mathrm{FVC}$ ratio and airway resistance did not differ when age and size were adjusted for. It is interesting that Miller et al. (1970) found similar $F E V_{1} / F V C$ ratios in African and Indian adults in Guyana.

There is little data available directly comparing white with either black or Asian females. Miller $e$ al. (1970) found no difference in $F E V_{1} / F V C$ ratio between African and Indian females in Guyana. Despite our Asian women being younger, their PEFR values were well below the values for blacks and whites (Table 1). This difference was confirmed by multiple regression analysis (Table 2). Despite the small sample size, the interpretation must be that there is a genuine effect of ethnic group in Asian women. There is no reason to believe that the PEFR readings themselves were spurious because of poor technique. In general, those Asian females that were studied had at least as good a comprehension of English as the Asian males and in both cases interpreters were used when necessary. Further, when technique is poor, a greater disparity is usually seen between the individual PEFR readings-this was not observed.

\section{References}

AbRAmowitz, S., LeINER, G.C., LEWIS, W.A. \& SMALL, M.J. (1965) Vital capacity in the negro. American Review of Respiratory Diseases, 92, 287.

BEEVERS, D.G. (1981) Introduction to 'Ethnic differences in common diseases' symposium. Postgraduate Medical Journal, 57, 747.

COTES, J.E. \& MALHOTRA, M.S. (1965) Differences in lung function between Indians and Europeans, Journal of Physiology, London, $177,17$.

DAMON, A. (1966) Negro white differences in pulmonary function (vital capacity, timed vital capacity and expiratory flow rate), Human Biology, 38, 380.

GoULD, B.A. (1869) Investigations in the military and anthropological statistics of American soldiers. Hurd and Houghton, New York.

GregG, I. \& NUNN, A.J. (1973) Peak expiratory flow in normal subjects. British Medical Journal, 3, 282.

JACKSON, S.H.D., BANNAN, L.T. \& BeEVERS, D.G. (1981) Ethnic differences in respiratory disease. Postgraduate Medical Journal, 57, 777.

MALIK, M.A., Moss, E. \& LEE, W.R. (1972) Prediction values for the ventilatory capacity in male West Pakistani workers in the United Kingdom. Thorax, 27, 611.

Miller, G.J., AshCroft, M.T., Swan, A.V. \& Beadnell, H.M. (1970) Ethnic variation in forced expiratory volume and forced vital capacity of African and Indian adults in Guyana. American Review of Respiratory Diseases, 102, 979.

WrIGHT, B.M. (1978) A miniature Wright peak flow meter. British Medical Journal, 2, 1627. 